\title{
Does intracytoplasmic sperm injection and the risk of gestational diabetes in patients with polycystic ovarian syndrome?
}

\author{
๑Tuğba Gürbüz ${ }^{1}$, @Nur Dokuzeylül Güngör ${ }^{2}$, ๑Arzu Yurci ${ }^{3}$ \\ ${ }^{1}$ Medistate Hospital, Gynecology and Obstetric Clinic, İstanbul, Turkey \\ ${ }^{2}$ Bahçeşehir University Göztepe Medical Park Hospital, Gynecology and In Vitro Fertilization Clinic, İstanbul, Turkey \\ ${ }^{3}$ Memorial Hospital, In Vitro Fertilization Clinic, Kayseri, Turkey
}

Cite this article as: Gürbüz T, Dokuzeylül Güngör N, Yurci A. Intracytoplasmic sperm injection and the risk of gestational diabetes in patients with polycystic ovarian syndrome. Anatolian Curr Med J 2021; 3(1); 53-58.

\begin{abstract}
Aim: Some studies found that in vitro fertilization (IVF) pregnancies were correlated with an increase in the incidence of gestational diabetes mellitus (GDM). The purpose of this study was to determine the effect of intracytoplasmic sperm injection (ICSI) on the risk of GDM in patients with polycystic ovary syndrome (PCOS).

Material and Method: This retrospective study was conducted on 862 women below 40 who applied to gynecology and IVF clinic between January 2015 and May 2020. Their body mass index (BMI) was close to each other. They all had a single fetus, and they did not have a diabetes history. The individuals who participated in the study were tested based on the $75 \mathrm{~g}$ oral glucose tolerance test (OGTT). Demographical characteristics, biochemical findings, and treatment styles were evaluated. Those with GDM history in the previous pregnancy were excluded from the study.

Results: The mean age and BMI of the patients and the differences observed in the control and case groups were not statistically significant $(\mathrm{p}>0.05)$. Preprandial $(\mathrm{p}<0.0001), 1^{\text {st }}$-hour blood glucose levels of OGTT $(\mathrm{p}<0.001)$, and $2^{\text {nd }}$-hour blood glucose levels of OGTT $(\mathrm{p}<0.0001)$ of the case group were statistically higher than those in the control group $(\mathrm{p}<0.05)$.

Conclusion: The confirmation of the indicators which increase the risk of GDM development with PCOS and follow-up in the early pregnancy period might minimize maternal and fetal complications depending on GDM. This study is significant since it investigates the effect of ICSI in patients with PCOS, spontaneous, and IVF pregnancies.
\end{abstract}

Keywords: Gestational diabetes, polycystic ovarian syndrome, assisted reproductive techniques

\section{INTRODUCTION}

Gestational diabetes mellitus (GDM) is defined as intolerance of carbohydrates detected or diagnosed during pregnancy. Along with two-times higher prevalence in the high-risk group, it is reported that the condition causes complications in $8 \%$ to $9 \%$ of pregnancies. American Diabetes Association (ADA) reported in their research that $7 \%$ of pregnant women corresponding to 200,000 pregnant women developed GDM per year (2). In Turkey, studies conducted in different centers report a prevalence rate varying between $1.9 \%$ and $27.9 \%$, with a prevalence average of 7.7\% (3-5). Pridjian and Benjamin (6) reported that there are multiple risk factors for gestational diabetes, and the most important risk factors include the history of GDM, obesity, and polycystic ovary syndrome (PCOS).
Polycystic ovary syndrome is a complex endocrine disorder characterized by anovulation, menstrual dysfunction, infertility, and hirsutism. This condition's typical form is associated with insulin resistance, abdominal obesity, dyslipidemia, and hyperinsulinemia; the condition increases the risk for type 2 diabetes and cardiovascular disease (7). On the other hand, PCOS is reported as an endocrine disease that affects $4 \%$ to $8 \%$ of women at childbearing age (8). In this respect, $40 \%$ of women diagnosed with PCOS are infertile due to anovulation.

The most common problem in PCOS is the early loss of pregnancy. It is predicted that almost $50 \%$ of women with PCOS are predicted to have a spontaneous miscarriage within the first trimester. Genetic factors and higher 
insulin levels increase the risk of miscarriage. In vitro fertilization is decided in patients who do not respond to metformin, Clomiphene Citrate (CC), and gonadotropin treatment (10). Some studies found an association between pregnancy with IVF and an increase in the incidence of GDM $(11,12)$. Therefore, this study aimed to determine the effect of the ICSI procedure on the risk of GDM in patients with PCOS.

\section{MATERIAL AND METHOD}

All procedures were performed adhered to the ethical rules and the Helsinki Declaration of Principles. The study was approved by the Ethical Committee of Beykoz University (7/17/2020-01), and official consent of Goztepe Medical Park Hospital Complex of Bahcesehir University was obtained. This retrospective study was carried out in Gynecology and In vitro Fertilization clinic between January 2015 and May 2020. Pregnant women and their families were informed about the study objective, and their verbal consents were obtained. The patients were informed that previous patient files would be used during the research. They were free to be enrolled and leave the study at any time, and there would not be any research expense claimed to the family or social security institution, and individual information would be kept confidential.

Pregnant women with PCOS who have referred to Gynecology and In vitro Fertilization Clinic of Goztepe Medical Park Hospital within Bahcesehir University between January 2015 and May 2020 were retrospectively reviewed by collecting the data from electronic patient files. A total number of 862 pregnant women under 40 years of age with similar body mass index (BMI) who have a single fetus and do not have any history of diabetes were enrolled in the study. Among 862 patients, 478 patients were included in the control group, and 384 patients were included in the patient group. The control group consisted of 165 patients with $\operatorname{PCOS}(+) \operatorname{GDM}(+)$ and spontaneous pregnancy, and 313 patients with PCOS(+)GDM(-) and spontaneous pregnancy. Patients enrolled in the patient group included 133 patients with $\mathrm{PCOS}(+) \mathrm{GDM}(+)$ assisted reproductive techniques (ART) pregnancy and 251 patients with $\mathrm{PCOS}(+) \operatorname{GDM}(-)$ and ART pregnancy. According to BMI, in the ICSI group, gonadotropin stimulation was started by applying 112,5-225 IU rFSH on the second or third day of the menstrual cycle. In all patients, an antagonist protocol was used. Serial vaginal ultrasonography was used to monitor ovarian response. In order to prevent premature luteinization, $0.25 \mathrm{lg} \mathrm{GnRH}$ (Cetrotide $250 \mathrm{lg}$, Merck Serono, Jordan, Turkey) antagonist was added daily when the leading follicle reached a diameter of $14 \mathrm{~mm}$. When the mean diameter of two or three leading follicles reached $18 \mathrm{~mm}$ or more, recombinant human chorionic gonadotropin (rHCG) (Ovitrelle $250 \mathrm{lg}$, Merck Serono, Jordan, Turkey) was used to trigger ovulation. Approximately 34-36 h after the rHCG injection, the oocytes were harvested transvaginally under general anesthesia. ICSI was then performed 3-4 h later.

Oral glucose tolerance test (OGTT) with 75 grams of glucose, demographic characteristics of individuals, biochemical findings, and treatments performed were evaluated. Individuals with a history of GDM in previous pregnancy were excluded. Differences between the data collected from patients were reviewed for the control and patient groups. Along with the review, patients in the control group were examined, whereas patients of the patient group were reviewed within their group.

\section{Statistical Analysis}

SPSS 23.0 package program was used for statistical analysis of the data. Categoric measurements were expressed in numbers and percentages; continuous measurements were expressed in mean, deviation, minimum, and maximum. Categoric variables were compared by Chi-square and fisher exact. Distribution of parameters was controlled in the analysis of continuous variables between groups; parameters with normal distribution were evaluated by Student t-test, and Mann Whitney-U test was implemented for parameters without normal distribution. The statistical significance level was determined as 0.05 for all tests used in the study.

\section{RESULTS}

Findings of the study's patients were reviewed in two groups as the control and case groups. Patients in the control group included 165 patients with PCOS(+) $\mathrm{GDM}(+)$ and spontaneous pregnancy and 313 patients with $\mathrm{PCOS}(+) \mathrm{GDM}(-)$ and spontaneous pregnancy. Patients in the case group included 133 patients with PCOS(+)GDM(+) and ART pregnancy and 251 patients with PCOS(+)GDM(-) and ART pregnancy. The review on patients included in the study revealed that there was not any significant difference between the control and case groups for age and BMI values ( $p>0.05$ ); however, gestational week of the patients at birth $(\mathrm{p}<0.0001)$, birth weight $(\mathrm{p}<0.0001)$, and total maternal weight gain $(p<0.0001)$ were detected higher in the control group when compared to the case group $(p<0.05)$ (Table 1). It was detected that ICSI procedure on patients with PCOS affected higher birth weight and total maternal weight gain, and lower gestational week at birth. 


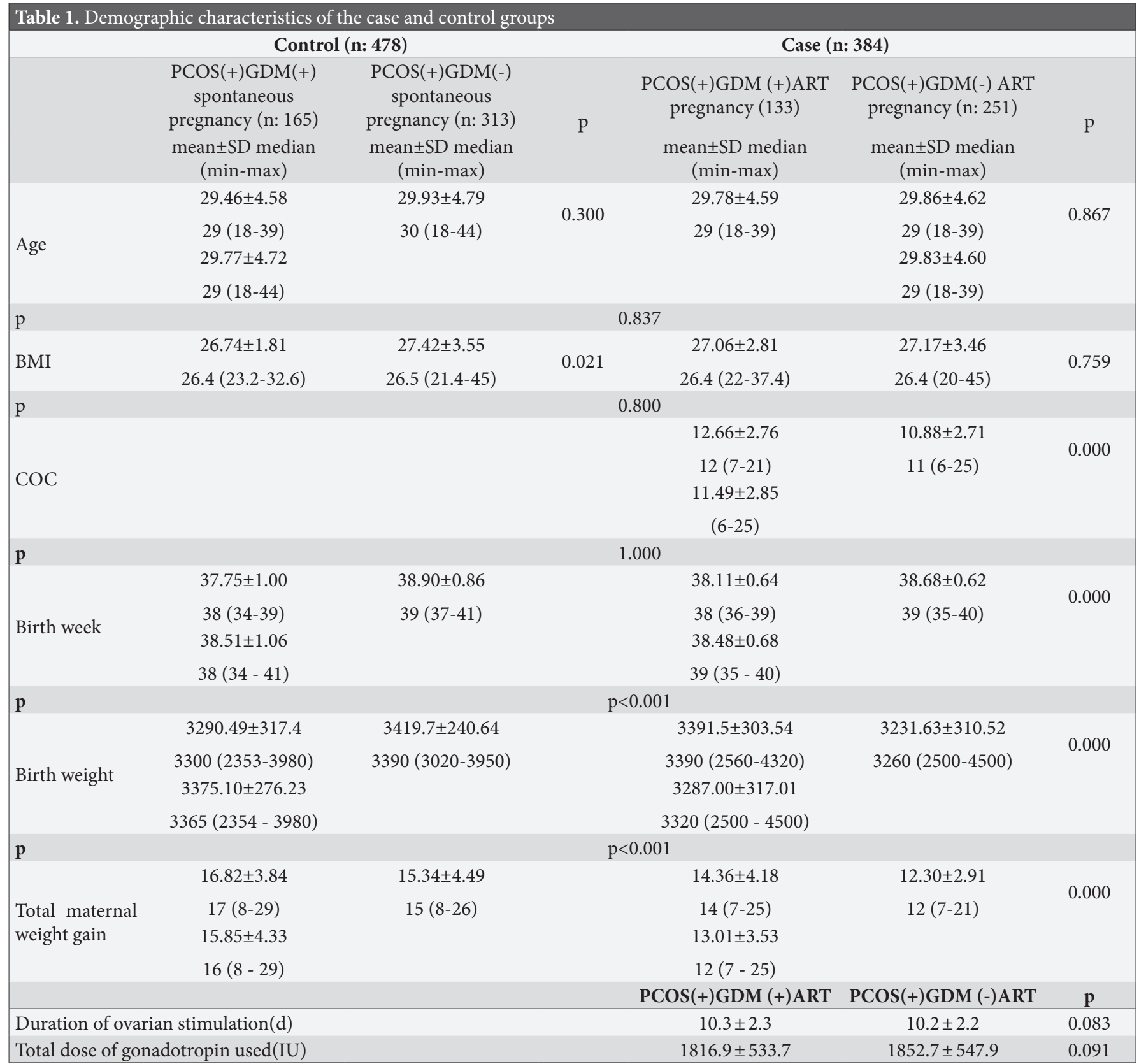

A review of patients in the control group, including 165 patients with $\operatorname{PCOS}(+) \operatorname{GDM}(+)$ and spontaneous pregnancy, and 313 patients with $\operatorname{PCOS}(+) \operatorname{GDM}(-)$ and spontaneous pregnancy revealed that there was not any significant difference between the groups for age ( $p>0.05)$; however, there was a statistically significant elevation in BMI $(\mathrm{p}<0.021)$, birth weight $(\mathrm{p}<0.0001)$, and birth weight $(\mathrm{p}<0.0001)$ levels of patients with $\mathrm{PCOS}(+)$ $\operatorname{GDM}(+)(\mathrm{p}<0.05)$. Total maternal weight gain findings of patients with $\operatorname{PCOS}(+) \operatorname{GDM}(+)$ and spontaneous pregnancy were statistically higher than average levels of patients with PCOS(+)GDM(-) and spontaneous pregnancy $(\mathrm{p}<0.05)$. This finding obtained increased the birth week and birth weight and decreased total maternal weight gain in patients with $\operatorname{PCOS}(+) \operatorname{GDM}(-)$ and spontaneous pregnancy in the control group.
There was not any difference between the age $(\mathrm{p}<0.867)$ and BMI $(\mathrm{p}<0.759)$ in patients of the case group, including 133 patients with $\mathrm{PCOS}(+) \mathrm{GDM}(+)$ and ART pregnancy, and 251 patients with PCOS(+)GDM(-) and ART pregnancy $(\mathrm{p}>0.05)$. Higher levels of Cumulus Oophorus Complex $(\mathrm{COC})(\mathrm{p}<0.0001)$, birth weight $(\mathrm{p}<0.0001)$, and total maternal weight gain $(\mathrm{p}<0.0001)$, and lower levels of the birth week in patients with PCOS $(+) \operatorname{GDM}(+)$ and ART pregnancy $(\mathrm{p}<0.05)$ than patients with $\operatorname{PCOS}(+) \operatorname{GDM}(-)$ and ART pregnancy were statistically significant $(\mathrm{p}<0.05)$. Such finding suggested that the $\mathrm{COC}$ ratio increases the birth weight and total maternal weight gain in patients with GDM and ART-PCOS; the birth week was earlier.

Fasting Blood Glucose $(\mathrm{FBG})$ level $(\mathrm{p}<0.0001)$, and OGTT levels at hours $1(\mathrm{p}<0.0001)$ and $2(\mathrm{p}<0.0001)$ 
of the patients in the case group was found significantly higher than the patients in the control groups $(\mathrm{p}<0.05)$. It was understood that the ICSI procedure in patients with PCOS increases FBG and OGTT levels at hours 1 and 2.

It was detected that normal birth $(\mathrm{p}<0.002)$, insulin use state $(\mathrm{p}<0.0001)$, GDM $(\mathrm{p}<0.0001)$, and multiparity $(p<0.0001)$ rates of the patients in the control group were significantly higher in the patients of the case group ( $\mathrm{p}<0.05)$ (Table2). It was detected that the ICSI procedure is not effective on normal birth, insulin use, GDM, and multiparity.

A review of the findings of the control group revealed that patients in the PCOS(+)GDM(+) and spontaneous pregnancy sub-group presented significantly higher fasting blood glucose $(\mathrm{p}<0.0001)$, OGTT levels at hours $1(\mathrm{p}<0.0001)$ and $2(\mathrm{p}<0.0001)$ than the patients in the PCOS $(+) G D M(-)$ sub-group $(\mathrm{p}<0.05)$. The multiparity of patients in the PCOS(+)GDM(-) group and spontaneous pregnancy $(\mathrm{p}<0.0001)$ was significantly higher in patients in the $\operatorname{PCOS}(+) \operatorname{GDM}(+)$ group $(\mathrm{p}<0.05)$. The insulin use and GDM in patients in the $\operatorname{PCOS}(+) \mathrm{GDM}(+)$ and spontaneous pregnancy subgroup were found significantly higher in the PCOS(+) $\operatorname{GDM}(-)$ sub-group $(\mathrm{p}<0.05)$ (Table 2).
FBG $(\mathrm{p}<0.0001)$, OGTT results at hours $1 \quad(\mathrm{p}<0.0001)$ and $2(\mathrm{p}<0.0001)$ were significantly higher in the patients with $\mathrm{PCOS}(+) \mathrm{GDM}(+)$ and ART pregnancy than those in the PCOS $(+) \mathrm{GDM}(-)$ sub-group $(\mathrm{p}<0.05)$. This finding suggested that an increase in fasting blood glucose and OGTT at hours 1 and 2 and GDM increases the use of insulin in patients with GDM and ART-PCOS. There was not any significant difference between patients with PCOS(+)GDM(+) and patients with PCOS(+)GDM(-) in the case group depending on the gravida and delivery style. Insulin use $(\mathrm{p}<0.0001)$ of the patients included in PCOS(+)GDM(-) sub-group was significantly higher than patients in the PCOS-GDM subgroup $(\mathrm{p}<0.05)$ (Table 2).

Table 3 presents that $59.1 \%$ (n: 81 ) of the patients had higher initial FBG levels whereas 42.1\% (n: 77) had higher OGTT levels at hour 1; 77.5\% (n: 93) of the patients had higher OGTT levels at hour 2.

\begin{tabular}{|llcc|}
\hline \multicolumn{4}{|c|}{ Table 3. Oral glucose tolerance test } \\
\hline & Frequency (\%) & Percentage (\%) \\
\hline \multirow{2}{*}{ Higher FBG } & No & 56 & 40.9 \\
\multirow{3}{*}{ OGTT Hour 1 Higher } & No & 81 & 59.1 \\
& Yes & 77 & 57.9 \\
\multirow{2}{*}{ OGTT Hour 2 Higher } & No & 27 & 42.1 \\
& Yes & 93 & 22.5 \\
& & & 77.5 \\
\hline${ }_{\text {*BG: Fasting blood glucose }}$ & & & \\
\hline
\end{tabular}

\begin{tabular}{|c|c|c|c|c|c|c|c|}
\hline & & \multicolumn{2}{|c|}{ Control (n: 478) } & \multicolumn{4}{|c|}{ Case (n: 384) } \\
\hline & & $\begin{array}{c}\text { Spontaneous PCOS } \\
\text { with GDM } \\
\text { (n: } 165)\end{array}$ & $\begin{array}{l}\text { PCOS without } \\
\text { GDM } \\
\text { (n: } 313)\end{array}$ & $\mathrm{p}$ & $\begin{array}{c}\text { ART-PCOS with } \\
\text { GDM } \\
\text { (n: } 133)\end{array}$ & $\begin{array}{l}\text { ART-PCOS without } \\
\text { GDM } \\
\text { (n: } 251)\end{array}$ & $\mathrm{p}$ \\
\hline & & $\mathrm{n}(\%)$ & $\mathrm{n}(\%)$ & & & $\mathrm{n}(\%)$ & \\
\hline Fasting blood glucose & $\begin{array}{l}\text { Lower } \\
\text { Higher }\end{array}$ & $\begin{array}{l}84(50.9) \\
81(49.1)\end{array}$ & $\begin{array}{c}313(100) \\
0(0.0)\end{array}$ & 0.000 & $\begin{array}{l}77(57.9) \\
56(42.1)\end{array}$ & $\begin{array}{c}250(99.6) \\
1(0.4)\end{array}$ & 0.000 \\
\hline p & & 0.000 & & & & & \\
\hline OGTT Hour 1 & $\begin{array}{l}\text { Lower } \\
\text { Higher }\end{array}$ & $\begin{array}{l}89(53.9) \\
76(46.1)\end{array}$ & $\begin{array}{c}313(100) \\
0(0.0)\end{array}$ & 0.000 & $\begin{array}{l}28(21.1) \\
105(78.9)\end{array}$ & $\begin{array}{c}251(100) \\
0(0.0)\end{array}$ & 0.000 \\
\hline $\mathbf{p}$ & & 0.000 & & & & & \\
\hline OGTT Hour 2 & $\begin{array}{l}\text { Lower } \\
\text { Higher }\end{array}$ & $\begin{array}{l}72(43.6) \\
93(56.4)\end{array}$ & $\begin{array}{c}313(100) \\
0(0.0)\end{array}$ & 0.000 & $\begin{array}{l}106(79.7) \\
27(20.3)\end{array}$ & $\begin{array}{c}251(100) \\
0(0.0)\end{array}$ & 0.000 \\
\hline p & & 0.000 & & & & & \\
\hline Gravida & $\begin{array}{l}\text { Nulliparous } \\
\text { Multiparous }\end{array}$ & $\begin{array}{c}122(73.9) \\
43(26.1)\end{array}$ & $\begin{array}{l}136(43.5) \\
177(56.5)\end{array}$ & 0.000 & $\begin{array}{c}126(94.7) \\
7(5.3)\end{array}$ & $\begin{array}{c}236(94.0) \\
15(6.0)\end{array}$ & 1.000 \\
\hline p & & 0.000 & & & & & \\
\hline Delivery & $\begin{array}{l}\text { C-section } \\
\text { Vaginal delivery }\end{array}$ & $\begin{array}{c}126(76.4) \\
39(23.6)\end{array}$ & $\begin{array}{c}240(76.7) \\
73(23.3)\end{array}$ & 1.000 & $\begin{array}{l}110(82.7) \\
23(17.3)\end{array}$ & $\begin{array}{c}222(88.4) \\
29(11.6)\end{array}$ & 0.12 \\
\hline p & & 0.001 & & & & & \\
\hline Insulin & $\begin{array}{l}\text { Yes } \\
\text { None }\end{array}$ & $\begin{array}{c}33(20.0) \\
132(80.0)\end{array}$ & $\begin{array}{c}0(0.0) \\
313(100)\end{array}$ & 0.000 & $\begin{array}{l}14(10.5) \\
119(89.5)\end{array}$ & $\begin{array}{c}0(0.0) \\
251(100)\end{array}$ & 0.000 \\
\hline p & & 0.000 & & & & & \\
\hline GDM & $\begin{array}{l}\text { Present } \\
\text { Absent }\end{array}$ & $\begin{array}{c}165(100) \\
0(0.0)\end{array}$ & $\begin{array}{c}0(0.0) \\
313(100)\end{array}$ & 0.000 & $\begin{array}{c}133(100) \\
0(0.0)\end{array}$ & $\begin{array}{c}0(0.0) \\
251(100)\end{array}$ & 0.000 \\
\hline p & & 0.000 & & & & & \\
\hline
\end{tabular}




\section{DISCUSSION}

Studies conducted in previous years reported that women with PCOS have a comparable probability of birth compared with controls without PCOS. However, a recent and comprehensive study conducted in Sweden found that women with PCOS have lower fertility rates and give birth to fewer children than women without PCOS throughout their lives. Many studies indicated that PCOS is an independent risk factor for GDM (14-16). There is insufficient data in the literature regarding the effects of ICSI application on GDM risk in PCOS patients.

While $50 \%$ of the patients diagnosed with PCOS have obesity, there is a significant weight gain history before menstrual disorders in most of the cases (17). In this context, it is stated that the presence of obesity in PCOS is an android type of obesity. It is inevitable to observe a metabolic activity due to the accumulation of adipose tissue in the visceral mesenteric regions of the abdominal walls of those with Android-type obesity and the accumulated adipose tissue's sensitivity to catecholamines (18). However, it may be stated that android-type fat distribution is a factor that increases the incidence of hyperinsulinemia, glucose intolerance, and diabetes mellitus (DM) in patients (19). Studies have confirmed this, and it was reported that the increase in androgens observed in patients with PCOS is a factor that decreases SHBG levels of patients but causes an increase in free testosterone and E2 levels (17-19). Clinical symptoms include hirsutism, menstrual irregularities, obesity, infertility, as well as long-term risks, endometrial cancer, type II diabetes mellitus, cardiovascular disease, hypertension, and dyslipidemia (20).

In a study, age and BMI averages of women with GDM+PCOS were $29.3 \pm 3.4$ years and $22.9 \pm 1.9 \mathrm{~kg} / \mathrm{m}^{2}$, respectively; and $30.8 \pm 3.2$ years and $21.4 \pm 1.9 \mathrm{~kg} / \mathrm{m}^{2}$, respectively in women with GDM-PCOS. There were not any significant differences for age and $\mathrm{BMI}$ in comparison of the groups $(\mathrm{p}<0.05)(21)$. In a study investigating the effects of insulin resistance and obesity on ICSI procedure in women with PCOS, the average age was $29.7 \pm 1.8$; 51 of the patients were normal according to the BMI classification, 27 were overweight, and 28 were obese (22). The incidence of GDM was significantly higher in obese patients than in non-obese patients and younger patients over 35 years of age in a previous study (23). A limited number of studies suggested that BMI is a better predictor than PCOS for the diagnosis of GDM and raises questions about the causeeffect relationship between PCOS and GDM (24). In our study, the differences observed in the control and case groups for the age and BMI values in the ICSI procedure, and insulin resistance and obesity in women with PCOS were not statistically significant $(\mathrm{p}<0.05)$. Since higher pregnancy age may cause many risks, it is difficult to reveal a clear conclusion that GDM solely may increase the risk.
In a study including 215 women with spontaneous pregnancy and 145 patients with ART pregnancy over the age of 40 , the incidence of GDM is higher by $43 \%$ in IVF/ ICSI pregnancy than spontaneous pregnancy. In another study, they found that GDM increases in IVF/ICSI single pregnancies compared to spontaneous pregnancies (12). In our study, fasting blood glucose $(\mathrm{p}<0.0001)$, OGTT levels at hours $1(\mathrm{p}<0.0001)$ and $2(\mathrm{p}<0.0001)$ were found significantly higher in patients in the case group than patients in the control group $(\mathrm{p}<0.05)$. A review of the findings of the control group revealed that patients in the PCOS $(+) \mathrm{GDM}(+)$ group had higher levels in fasting blood glucose $(\mathrm{p}<0.0001)$ and OGTT levels at hours 1 and 2 than patients in the PCOS(+)GDM(-) sub-group $(p<0.05)$. This study reveals that it is important to evaluate pregnant women in terms of carbohydrate intolerance in the early period in pregnancies caused by ICSI in patients with PCOS. Along with timely diet and physical activity intervention, early diagnosis and treatment of carbohydrate intolerance in pregnancies after ART may prevent excessive weight gain and development of GDM during pregnancy.

In a study conducted by Aktun et al. (16) on patients with PCOS and GDM without PCOS, no significant differences were found between the groups in cesarean delivery. In a study conducted on the effects of IVF application on pregnancy outcomes in patients with PCOS, it was reported that the differences between the groups in terms of cesarean delivery were not significant for the groups $(p>0.05)$. Contrary to the literature, differences obtained between the groups were significant in our study $(\mathrm{p}<0.002)$.

In a study, there was not any statistically significant difference for weight gain between patients with GDM(+)PCOS and patients with GDM(-)PCOS (16). In a study in which pregnancy results were evaluated in controls matched with age and weight in women with PCOS, the differences between the groups were not found to be significant $(p<0.05)$. Contrary to the literature, a significant difference was found between the groups regarding weight gain in our study $(\mathrm{p}<0.05)$. This situation may be explained by the homogeneity of the characteristics of the individuals participating in the study.

In a study evaluating maternal and live birth results after ART, no significant differences were found between IVF/ICSI and spontaneous pregnancies in terms of low birth weight (12). A study examining the birth weight of babies of individuals with PCOS found that low birth weight babies were more common in individuals with PCOS (26). Literature reveals different outcomes on this subject. Our findings detected a significant difference between the groups $(\mathrm{p}<0.05)$. 


\section{CONCLUSION}

Several studies are suggesting that PCOS is a risk factor for the development of GDM. Identification of the markers that increase the risk of GDM development in PCOS patients will enable these patients to be examined in detail in case of pregnancy and to minimize maternal and fetal complications due to GDM. Our study is important in examining the effect of ICSI application on GDM in cases with PCOS diagnosis and spontaneous or ART pregnancies.

\section{ETHICAL DECLARATIONS}

Ethics Committee Approval: The study was approved by the Ethical Committee of Beykoz University (7/17/202001), and official consent of Goztepe Medical Park Hospital Complex of Bahcesehir University was obtained.

Informed Consent: Because the study was designed retrospectively, no written informed consent form was obtained from patients.

Referee Evaluation Process: Externally peer-reviewed. Conflict of Interest Statement: The authors have no conflicts of interest to declare.

Financial Disclosure: The authors declared that this study had received no financial support.

Author Contributions: All of the authors declare that they have all participated in the design, execution, and analysis of the paper and that they have approved the final version.

\section{REFERENCES}

1. DeSisto CL, Kim SY, Sharma AJ. Prevalence Estimates of Gestational Diabetes Mellitus in the United States, Pregnancy Risk Assessment Monitoring System (PRAMS), 2007-2010. Prev Chronic Dis 2014; 11: 104.

2. American Diabetes Association. Diagnosis and classification of diabetes mellitus. Diabetes Care 2011; 34: 62-9.

3. Karaçam Z, Çelik D. The prevalence and risk factors of gestational diabetes mellitus in Turkey: a systematic review and meta-analysis. J Matern Fetal Neonatal Med 2019; 2: 1-11.

4. Karçaaltıncaba D, Çalıș P, Öcal N, Özek A, Altuğ İnan M, Bayram M. Prevalence of gestational diabetes mellitus evaluated by universal screening with a 75-g, 2-hour oral glucose tolerance test and IADPSG criteria. Int J Gynaecol Obstet 2017; 138: 148-51.

5. Çabuk E, Duru SA, Akal C, Olten B, Eroğlu D, Yanık FF. Maternal characteristics and perinatal outcomes in pregnancies with abnormal $50 \mathrm{~g}$ oral glucose challenge test and normal $100 \mathrm{~g}$ oral glucose test results. Poster Presentation. The 4th Congress of the South-East European Society of Perinatal Medicine 20-21 May 2011, Bucharest, Romania.

6. Pridjian G, Benjamin TD. Update on gestational diabetes. Obstet Gynecol Clin North Am 2010; 37: 255-67.

7. Kakoly N, Moran L, Teede H, Joham A. Cardiometabolic risks in PCOS: A review of the current state of knowledge. Expert Rev Endocrinol Metab 2019; 14: 23-33.

8. Azziz R, Woods KS, Reyna R, Key TJ, Knochenhauer ES, Yildiz BO. The prevalence and features of the polycystic ovary syndrome in an unselected population. J Clin Endocrinol Metab 2004; 89: 2745-9.
9. Diamanti-Kandarakis $\mathrm{E}$, Dunaif $\mathrm{A}$. Insulin resistance and the polycystic ovary syndrome revisited: an update on mechanisms and implications. Endocr Rev 2012; 33: 981-1030.

10. Costello MF, Misso ML, Wong J, et al. The treatment of infertility in polycystic ovary syndrome: a brief update. Aust N Z J Obstet Gynaecol 2012; 52: 400-3.

11. Persson S, Elenis E, Turkmen S, Kramer MS, Yong EL, Sundstro" $\mathrm{m}$-Poromaa I. Fecundity among women with polycystic ovary syndrome (PCOS)-a population-based study. Human Reproduction 2019; 34: 2052-60.

12. Yang X, Li Y, Li C, Zhang W. Current overview of pregnancy complications and live-birth outcome of assisted reproductive technology in mainland China. Fertil Steril 2014; 101: 385-91.

13. Zhu L, Zhang Y, Liu Y, et al. Maternal and live-birth outcomes of pregnancies following assisted reproductive technology: a retrospective cohort study. Sci Rep 2016; 6: 35141.

14. Roos N, Kieler H, Sahlin L, Ekman-Ordeberg G, Falconer H, Stephansson O. Risk of adverse pregnancy outcomes in women with polycystic ovary syndrome: population-based cohort study. BMJ 2011; 343: 6309.

15. Rees DA, Jenkins-Jones S, Morgan CL. Contemporary reproductive outcomes for patients with polycystic ovary syndrome: a retrospective observational study. Journal of Clinical Endocrinology and Metabolism 2016; 101: 1664-72.

16. Mumm H, Jensen DM, Sørensen JA, et al. Hyperandrogenism and phenotypes of polycystic ovary syndrome are not associated with differences in obstetric outcomes. Acta Obstet Gynecol Scand 2015; 94: 204-11.

17. Aktun HL, Yorgunlar B, Acet M, Aygun BK, Karaca N. The effects of polycystic ovary syndrome on gestational diabetes mellitus. Gynecological Endocrinology 2016; 32 ; 139-42.

18. Taylor Ann E. Polycystic Ovary Syndrome Endocrinol Metab Clin North Am 1998; 27: 877-903.

19. Futterweit W. Polycystic Ovary Syndrome: Clinical Perspectives and Management. Obstet Gynaecol Survey 1999: 18: 403-13.

20. Speroff L, Fritz MA. Clinical Gyneacologic Endocrinology and Infertility. 7 th Edition, 2007: 470-91; 1177-205.

21. Devroey P, Bourgain C, Macklon NS,Fauser BC. Reproductive biology and IVF: ovarian stimulation and endometrial receptivity. Trends Endocrinol Metab 2004; 15: 84-90.

22. Cakiroglu Y, Doger E, Vural F, Kopuk SY, Vural B. Impact of insulin resistance and obesity on intracytoplasmic sperm injection outcomes in young women with polycystic ovary syndrome. North Clin Istanb 2017; 4: 218-24.

23. Cozzolino M, Serena C, Maggio L, et al. Analysis of the main risk factors for gestational diabetes diagnosed with International Association of Diabetes and Pregnancy Study Groups (IADPSG) criteria in multiple pregnancies. J Endocrinol Invest 2017; 40: 93743.

24. Turhan NO, Seçkin NC, Aybar F and Inegöl I. Assessment of glucose tolerance and pregnancy outcome of polycystic ovary patients. Int J Gynaecol Obstet 2003; 81: 163-68.

25. Ashrafi M, Gosili R, Hosseini R, Arabipoor A, Ahmadi J, Chehrazi M. Risk of gestational diabetes mellitus in patients undergoing assisted reproductive techniques. Eur J Obstet Gynecol Reprod Biol 2014; 176: 149-52.

26. Sir-Petermann T, Hitchsfeld C, Maliqueo M, et al. Birth weight in offspring of mothers with polycystic ovarian syndrome. Hum Reprod 2005; 20: 2122-6. 